\title{
Oxygen therapy in myocardial infarction
}

\author{
R. LANCASTER* \\ M.A., M.R.C.P.
}

\author{
M. W. McNicOL \\ M.D., M.R.C.P.
}

Cardiothoracic Department, Central Middlesex Hospital, London, N.W.10

High concentration oxygen therapy is often required after acute myocardial infarction, as hypoxia is common and may be resistant to oxygen therapy (MacKenzie et al., 1964 ; McNicol et al., 1965). While $100 \%$ oxygen is probably the treatment of choice, the apparatus for its administration, a tight-fitting face mask with valve box and reservoir or demand valve, is poorly tolerated and requires constant supervision. Of the other methods of high concentration oxygen therapy available, none is ideal. Disposable plastic face masks are widely used, but are poorly tolerated by the patient and unstable on the face. The M.C. mask was introduced by Catterall (1960) as a means of giving oxygen at low flow-rates. A recent study has shown it to be efficient at high flow-rates also, in cases of respiratory disease, if there is no carbon dioxide retention (Catterall, Kazantzis \& Hodges, 1967). It is well tolerated, stable and requires little supervision. This paper reports an assessment of its efficiency as a method of high concentration oxygen therapy in patients with myocardial infarction.

\section{The patients}

The patients were men aged $36-68$ years. Fifteen had unequivocal evidence of infarction. In five $(4,7,12,15$ and 16$)$ who had episodes of myocardial ischaemia clinically, infarction was not proven. All were studied within $48 \mathrm{hr}$ of admission to hospital and in twelve patients there was evidence of left ventricular failure at the time of study.

\section{Methods}

Oxygen therapy

Oxygen was administered by M.C. mask. Arterial blood samples were taken breathing air and after breathing oxygen for $20 \mathrm{~min}$ at both 6 and $101 / \mathrm{min}$. In ten patients oxygen tensions were measured after breathing $100 \% \mathrm{O}_{2}$ for $10 \mathrm{~min}$ via valve box and reservoir bag.

*Present address: Department of Medicine, The Middlesex Hospital, London, W.1.
Arterial samples were taken via an indwelling Teflon arterial cannula (Longdwel, BectonDickinson) in the brachial artery. The samples were taken into all-glass syringes, the dead space being filled with heparin $(5000 \mathrm{u} / \mathrm{ml})$. Analysis was carried out immediately.

Arterial oxygen tension was measured with a polarographic electrode (Radiometer, Copenhagen). The electrode was calibrated before each reading. Tonometry showed that this electrode has a gas-blood difference of $2 \mathrm{mmHg}$ at oxygen tension $150 \mathrm{mmHg}$ and $54 \mathrm{mmHg}$ at oxygen tension $700 \mathrm{mmHg} . \mathrm{PCO}_{2}$ was measured with a Severinghaus $\mathrm{CO}_{2}$ electrode.

\section{Results (Table 1)}

At an oxygen flow rate of $61 / \mathrm{min}$ all patients had an oxygen tension of over $100 \mathrm{mmHg}$. At $101 / \mathrm{min}$ all patients had an oxygen tension over $50 \mathrm{mmHg} ; 88 \%$ over $200 \mathrm{mmHg}$ and $24 \%$ over $300 \mathrm{mmHg}$. The oxygen tension after $100 \%$ oxygen is also shown and the 'efficiency' of the mask

\begin{tabular}{|c|c|c|c|c|}
\hline Patient No. & Air & $61 / \mathrm{min}$ & $10 \mathrm{l} / \mathrm{min}$ & $100 \%$ \\
\hline 1 & 62 & 146 & - & - \\
\hline 2 & 62 & 154 & - & - \\
\hline 3 & 58 & 178 & - & - \\
\hline 4 & 98 & - & 375 & - \\
\hline 5 & 43 & - & 354 & - \\
\hline 6 & 61 & - & 332 & - \\
\hline 7 & 79 & 221 & 254 & - \\
\hline 8 & 104 & 212 & 262 & - \\
\hline 9 & 67 & 182 & 276 & 400 \\
\hline 10 & 37 & 122 & 190 & - \\
\hline 11 & 67 & 132 & 158 & - \\
\hline 12 & 75 & 226 & 260 & 375 \\
\hline 13 & 78 & 292 & 296 & 435 \\
\hline 14 & 82 & 220 & 280 & 336 \\
\hline 15 & 84 & 224 & 282 & 455 \\
\hline 16 & 85 & 214 & 267 & 424 \\
\hline 17 & 65 & 172 & 234 & 490 \\
\hline 18 & 90 & 203 & 282 & 550 \\
\hline 19 & 76 & 178 & 224 & 420 \\
\hline 20 & 89 & 190 & 320 & 415 \\
\hline $\begin{array}{l}\text { Mean } \\
\text { SD }\end{array}$ & $\begin{array}{r}73 \\
\pm 16\end{array}$ & $\begin{array}{r}192 \\
\pm 40\end{array}$ & $\begin{array}{r}272 \\
+51\end{array}$ & $\begin{array}{r}430 \\
\pm 56\end{array}$ \\
\hline
\end{tabular}


gauged by comparing this with oxygen tension obtained after $101 / \mathrm{min}$ via the M.C. mask (Table 2). Using the M.C. mask at $10 \mathrm{l} / \mathrm{min}$, the oxygen tension was $65 \%$ that achieved after breathing $100 \%$ oxygen.

TABLE 2

\begin{tabular}{ccc}
$\begin{array}{c}\mathrm{PaO}_{2} \text { after using } \\
\text { compared }\end{array}$ with $\mathrm{PaO}_{2}$ after $100 \%$ oxygen \\
\hline Patient No. & \multicolumn{3}{c}{ Efficiency $(\%)$} \\
\hline 9 & $276 / 400$ & 69 \\
12 & $260 / 375$ & 69 \\
13 & $296 / 435$ & 68 \\
14 & $280 / 336$ & 84 \\
15 & $282 / 455$ & 62 \\
16 & $267 / 424$ & 63 \\
17 & $234 / 490$ & 48 \\
18 & $282 / 550$ & 51 \\
19 & $224 / 420$ & 55 \\
20 & $320 / 415$ & 77 \\
\hline
\end{tabular}

Mean efficiency $=65 \% ; \mathrm{SD}= \pm 9 \cdot 7$.

Fig. 1 shows the relationship between $\mathrm{PaO}_{2}$ and oxygen flow rate. The mean rise in oxygen tension was $20 \mathrm{mmHg} / 1 / \mathrm{min}$ increase in oxygen flow-rate but the scatter was wide, especially at the higher flow rates.

$\mathrm{PCO}_{2}$ showed no consistent change.

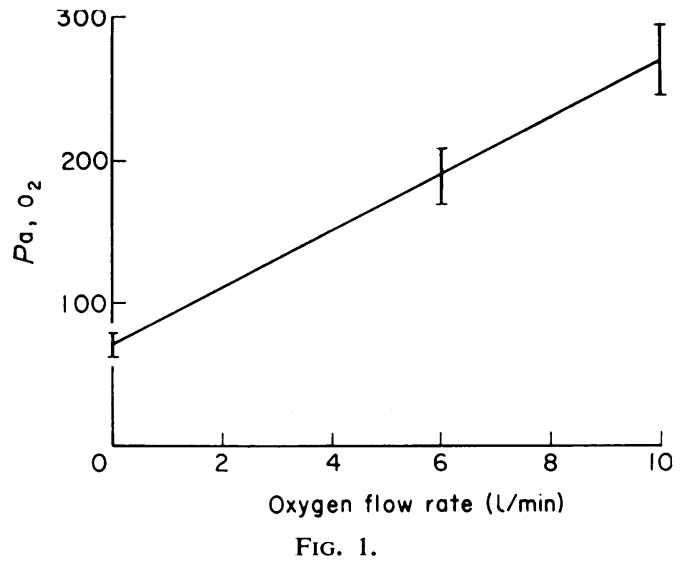

\section{Discussion}

The results show that the M.C. mask is an efficient method of giving high-concentration oxygen. At a flow rate of $101 / \mathrm{min}$ arterial oxygen tension exceeded $150 \mathrm{mmHg}$ in all patients. This oxygen tension is high enough to ensure full saturation of the haemoglobin.

Many of the patients studied had a low $\mathrm{PaO}_{2}$ breathing air, indicating impaired lung function, the result of myocardial infarction. In some, this was severe. These cases are frequently resistant to oxygen therapy (McNicol et al., 1965), but in all our cases the haemoglobin was fully saturated at $10 \mathrm{l} / \mathrm{min}$.

The difference between $50 \%$ and $100 \%$ 'efficiency' is only in terms of dissolved oxygen and in absolute amounts, is small (less than $1 \mathrm{ml} \mathrm{O}_{2} / 100$ $\mathrm{ml}$ blood). It has not been established that such a difference is significant.

From these results, we think that, at present, the M.C. mask, which is acceptable on clinical grounds, is efficient enough as a means of high concentration oxygen therapy to justify its general use in myocardial infarction.

\section{Summary}

The 'efficiency' of the M.C. mask as a means of giving high concentration oxygen after myocardial infarction was assessed. Arterial oxygen tensions were measured at flow rates of 6 and 10 $1 /$ min using the M.C. mask, and were compared with oxygen tension after breathing $100 \%$ oxygen. At $61 / \mathrm{min}$ the oxygen tension was over 100 $\mathrm{mmHg}$ in all cases and at $101 / \mathrm{min}$ over 150 $\mathrm{mmHg}$ in all cases. At $10 \mathrm{1} / \mathrm{min}$ the 'efficiency' of the M.C. mask was $65 \%$ that of $100 \%$ oxygen. It is concluded that the M.C. mask is effective and probably the best available method of routine high concentration oxygen therapy in myocardial infarction.

\section{References}

BaLl, J.A.C. (1961) The administration of oxygen. Lancet, i, 591.

Catterall, M. (1960) A new mask for delivering oxygen or other gases. Brit. med. J. i, 1941.

Catterall, M., Kazantzis, G. \& Hodges, M. (1967) The performance of nasal catheters and a face mask in oxygen therapy. Lancet, i, 415.

Mackenzie, G.J., Flenley, D.C., Taylor, S.H., McDonald, A.H., Staunton, H.P. \& Donald, K.W. (1964) Circulatory and respiratory studies in myocardial infarction and cardiogenic shock. Lancet, ii, 825.

MCNicol, M.W., Kirby, B.J., BhoOla, K.D., Everest, M.E., Price, H.V. \& Freedman, S.F. (1965) Pulmonary function in acute myocardial infarction. Brit. med. J. ii, 1270. 